This is the accepted version of the article:

Spinato C., Perez Ruiz De Garibay A., Kierkowicz M., Pach E., Martincic M., Klippstein R., Bourgognon M., Wang J.T.-W., Ménard-Moyon C., Al-J amal K.T., Ballesteros B., Tobias G., Bianco A.. Design of antibody-functionalized carbon nanotubes filled with radioactivable metals towards a targeted anticancer therapy. Nanoscale, (2016). 8. : 12626 - . $10.1039 /$ c5nr07923c.

Available at: https://dx.doi.org/10.1039/c5nr07923c 


\title{
Design of antibody-functionalized carbon nanotubes filled with radioactivable metals towards a targeted anticancer therapy
}

\author{
Cinzia Spinato, ${ }^{a}$ Aritz Perez Ruiz de Garibay, ${ }^{a}$ Magdalena Kierkowicz, ${ }^{b}$ Elzbieta Pach, ${ }^{\mathrm{c}}$ \\ Markus Martincic, ${ }^{b}$ Rebecca Klippstein, ${ }^{d}$ Maxime Bourgognon, ${ }^{d}$ Julie Tzu-Wen Wang, ${ }^{d}$ \\ Cécilia Ménard-Moyon, ${ }^{a}$ Khuloud T. Al-Jamal, ${ }^{d}$ Belén Ballesteros, ${ }^{c}$ Gerard Tobias, ${ }^{b^{\star}}$ \\ Alberto Bianco ${ }^{a^{*}}$
}

${ }^{a}$ CNRS, Institut de Biologie Moléculaire et Cellulaire, Laboratoire d'Immunopathologie et Chimie Thérapeutique, 67000 Strasbourg, France.

${ }^{\mathrm{b}}$ Institut de Ciència de Materials de Barcelona (ICMAB-CSIC), Campus UAB, 08193 Bellaterra, Barcelona, Spain.

${ }^{\mathrm{C}}$ Catalan Institute of Nanoscience and Nanotechnology (ICN2), CSIC and The Barcelona Institute of Science and Technology, Campus UAB, 08193 Bellaterra, Barcelona, Spain.

dInstitute of Pharmaceutical Science, Faculty of Life Sciences \& Medicine, King's College London, London SE1 9NH, UK.

Corresponding e-mail:

a.bianco@ibmc-cnrs.unistra.fr

gerard.tobias@icmab.es

KEYWORDS: Single-walled carbon nanotubes, filling, samarium, lutetium, drug delivery, radiotherapy, antibody targeting, cancer therapy

In the present work we have devised the synthesis of a novel promising carbon nanotube carrier for the targeted delivery of radioactivity, through a combination of endohedral and exohedral functionalization. Steam-purified single-walled carbon nanotubes (SWCNTs) have been initially filled with radioactive analogues (i.e. metal halides) and sealed by high temperature treatment, affording closed-ended CNTs with the filling material confined in the inner cavity. The external functionalization of these filled CNTs was then achieved by nitrene cycloaddition and followed by the derivatization with a monoclonal antibody (Cetuximab) targeting the epidermal growth factor receptor (EGFR), overexpressed by several cancer cells. The targeting efficiency of the soobtained conjugate was evaluated by immunostaining with a secondary antibody and by incubation of the CNTs with EGFR positive cells (U87-EGFR+), followed by flow cytometry, confocal microscopy or elemental analyses. We demonstrated that our filled and functionalized CNTs can internalize more efficiently in EGFR positive cancer cells. 


\section{INTRODUCTION}

Carbon nanotubes (CNTs) have shown many applications in the biomedical field thanks to their properties and the combination with covalent and/or non-covalent functionalization. ${ }^{1-4}$ For example, they have been employed as ultra-sensitive biosensors for glucose and DNA, nanocomposites for prosthetic devices or as drug delivery systems. ${ }^{2,4-6}$ To this purpose, their high surface area can be exploited to append multiple copies of bioactive and/or imaging molecules, creating an appropriate platform for the delivery of diagnostic and therapeutic agents. Moreover, their unique electrical, thermal and spectroscopic properties in the biological context offer further advantages in the detection, monitoring and therapy of diseases.

In contrast with the numerous and varied reports of CNT-conjugates for drug and gene delivery, ${ }^{5-7}$ only few studies exploring CNTs as carriers of radionuclides, either for imaging or therapeutic purposes, have been published. We were among the first to trace in vivo a radioactive CNT construct obtained by chelation of ${ }^{111}$ In (i.e. Y-emitter) to single-walled CNTs (SWCNTs) functionalized with the chelating molecule DTPA (diethylenetriamine pentaacetic acid). ${ }^{8}$ With a similar approach, Ruggiero et al. radiolabeled CNTs with ${ }^{225} \mathrm{Ac}$ (i.e. $\alpha$-emitter) and further functionalized with an antibody targeting the tumor neovasculature, achieving high tumor accumulation and reduction of the tumor volume of xenografted mice. ${ }^{9}$ Other examples of CNT radioimmuno-carriers have been reported combining CNT delivery properties with targeting antibodies and radionuclides, such as ${ }^{86} \mathrm{Y},{ }^{125} \mathrm{I},{ }^{14} \mathrm{C},{ }^{64} \mathrm{Cu}$ or ${ }^{99 \mathrm{~m}} \mathrm{Tc},{ }^{10-14}$ enabling radioimaging and even anticancer therapy. Wang et al. recently synthesized hybrids of multi-walled CNTs (MWCNTs) and magnetic nanoparticles, and further tethered technetium-99m, achieving dual MRI and SPECT imaging. ${ }^{14}$ In 2010, we reported an innovative example of CNT-based radiotracer obtained by exploiting the hollow interior of the tubes to encapsulate the radionuclide (i.e. sodium iodide-125, Auger and $\mathrm{y}$-emitter). ${ }^{15}$ The encapsulation of the metal halide by molten-phase capillary filling at high temperatures engendered sealed nanotubes with the internal material trapped inside ( $\mathrm{Na}^{125} \mathrm{I} @$ SWCNTs). The subsequent external functionalization of the CNTs with glycoconjugates enhanced the dispersibility and biocompatibility of the construct, which by SPECT/CT showed a different biodistribution profile in mice compared to free iodine. We also demonstrated that this CNT conjugate allowed the localized and safe delivery of an unprecedented radiodosage and remained stable in the biological milieu in vitro and in vivo without leakages of the radionuclide. These promising results prompted us to carry out further investigations by exploring the possibility to employ a different filling material, functionalization approach and targeting moiety to prepare a CNT-carrier for the targeted delivery of radiotherapy. Indeed, the choice of the filling radionuclide allows to tailor a specific radiation, cancer type and therapy. In parallel, the functionalization of the external surface offers versatility towards the appendage of targeting functionalities, thus enabling to modulate the biodistribution of the carrier. The monoclonal antibody $(m A b)$ Cetuximab (Erbitux $\left.{ }^{\circledR}\right)$ was selected as targeting agent for the functionalization of the filled nanotubes. This mAb has shown to efficiently target and inhibit the epidermal growth factor receptor (EGFR), a membrane receptor regulating multiple cellular processes and overexpressed in many cancer types. ${ }^{16}$ The clinical use of Cetuximab has been approved for the treatment of advanced chemo-refractory cancers such as colorectal cancer, non-small-cell lung cancer, head and neck cancer. ${ }^{17-19}$ Moreover, the conjugation of radionuclides to Cetuximab via metal chelation has been already investigated, with the goal of enhancing its therapeutic efficacy and achieve simultaneous tumor diagnosis and treatment. ${ }^{20} \mathrm{~A}$ few examples of Cetuximab-CNT conjugates have also been reported, ${ }^{21-23}$ showing good targeting properties toward EGFR-overexpressing cells. However, to the best of our knowledge, no example of radioactivity delivery by means of Cetuximab-labeled CNTs has been ever reported. It seemed to us very interesting to exploit the high targeting efficiency of this mAb to direct filled CNTs to specific tumor tissues. This investigation was carried out as a proof-of-concept using CNTs filled with model non-radioactive materials, with the aim of translating the whole process on radioactively-filled CNTs in a second phase. We studied a simple and quick protocol for the preparation of mAb-functionalized filled CNTs, taking care to keep the time of preparation as short as possible and to preserve the integrity of the nanotube structure, to avoid any leakage of the internal material. In order to tether the antibody to the nanotubes through a covalent approach, the CNT external surface was initially functionalized by a cycloaddition reaction with a suitable linker. The immobilization of the bioactive target onto the CNTs through a fully covalent approach was meant to ensure the in vivo stability of 
the final conjugate. The antibody-CNTs were then thoroughly characterized by different techniques, and their targeting ability was assessed in vitro in cancer cells overexpressing EGFR (U87 EGFR+). We demonstrated that our novel CNT-carrier is able to selectively accumulate into U87 cancer cells, while it is not uptaken by cancer cells which do not express this receptor.

\section{RESULTS AND DISCUSSION}

In the last decades, filled CNTs have found applicability in different areas ${ }^{24-26}$ particularly receiving increasing attention from the biomedical field, since their inner cavity can be occupied by therapeutic or imaging cargos, while the outer surface can be modified to convey dispersibility, biocompatibility and site-selectivity. ${ }^{26,27}$ The filling of carbon nanotubes with inorganic compounds, in the present case metal halides, can be achieved by molten-phase capillary wetting. ${ }^{28,29}$ Once filled, the process of cooling the system back to room temperature causes the dangling bonds at the ends of the nanotubes to seal by radical recombination. ${ }^{30}$ As a consequence, filled and sealed nanotubes are obtained, where the selected material is confined in the inner cavity.

\section{SWCNT purification and filling}

As-received single-walled CNTs (SWCNTs) were end-opened and purified prior to be filled with the selected payloads. Steam was employed as one of the purification steps, since it opens the ends of the SWCNTS, decreases the number of structural defects and removes carbonaceous impurities. ${ }^{31}$ The removal of the amorphous carbon allows an efficient sidewall functionalization of the tubes. ${ }^{32}$ Thermogravimetric analyses (TGA) of both the as-received and purified SWCNTs performed under flowing air allowed to quantify the amount of inorganic impurities in the samples, coming from the synthesis of the nanotubes. Compared to as-received material, which reveals 4.6 wt \% of inorganic solid residue, a decrease is observed for the purified samples down to 1.7-1.9 wt $\%$ (see ESI Figure S1).

Opened-ended and purified SWCNTs were next filled with two selected payloads, namely $\mathrm{SmCl}_{3}$ and $\mathrm{LuCl}_{3}$. The metal halides were encapsulated by molten phase high temperature filling, which results in the formation of filled closed-ended CNTs. ${ }^{30}$ The closed CNT ends allow the removal of the external material, using an appropriate solvent, whilst preserving the encapsulated compounds. The residue obtained after TGA of filled SWCNTs will still contain a fraction of the inorganic impurities present in the purified material but its major contribution now arises from the oxidation of the metal halides to the respective metal oxides $\left(\mathrm{Sm}_{2} \mathrm{O}_{3}\right.$ and $\mathrm{Lu}_{2} \mathrm{O}_{3}$, respectively) (see ESI Figure $\mathrm{S} 1$ ). From the performed thermogravimetric analyses it was possible to determine the filling yield of the encapsulated materials employing a previously reported formula. ${ }^{33}$ In the present case, the filling yield of SmCl ${ }_{3} @ S W C N T s(\mathbf{1 a})$ and $\mathrm{LuCl}_{3} @ S W C N T s$ (1) turned out to be 18.1 wt \% and 29.9 wt \%, respectively (see ESI Figure S1).

The encapsulation of the metal halides into SWCNTs was confirmed by electron microscopy imaging and spectroscopy. First, high angle annular dark field scanning transmission electron micrographs (HAADF-STEM) were acquired on a scanning electron microscope (SEM) operated at 20 kV (Figure 1a, b). 


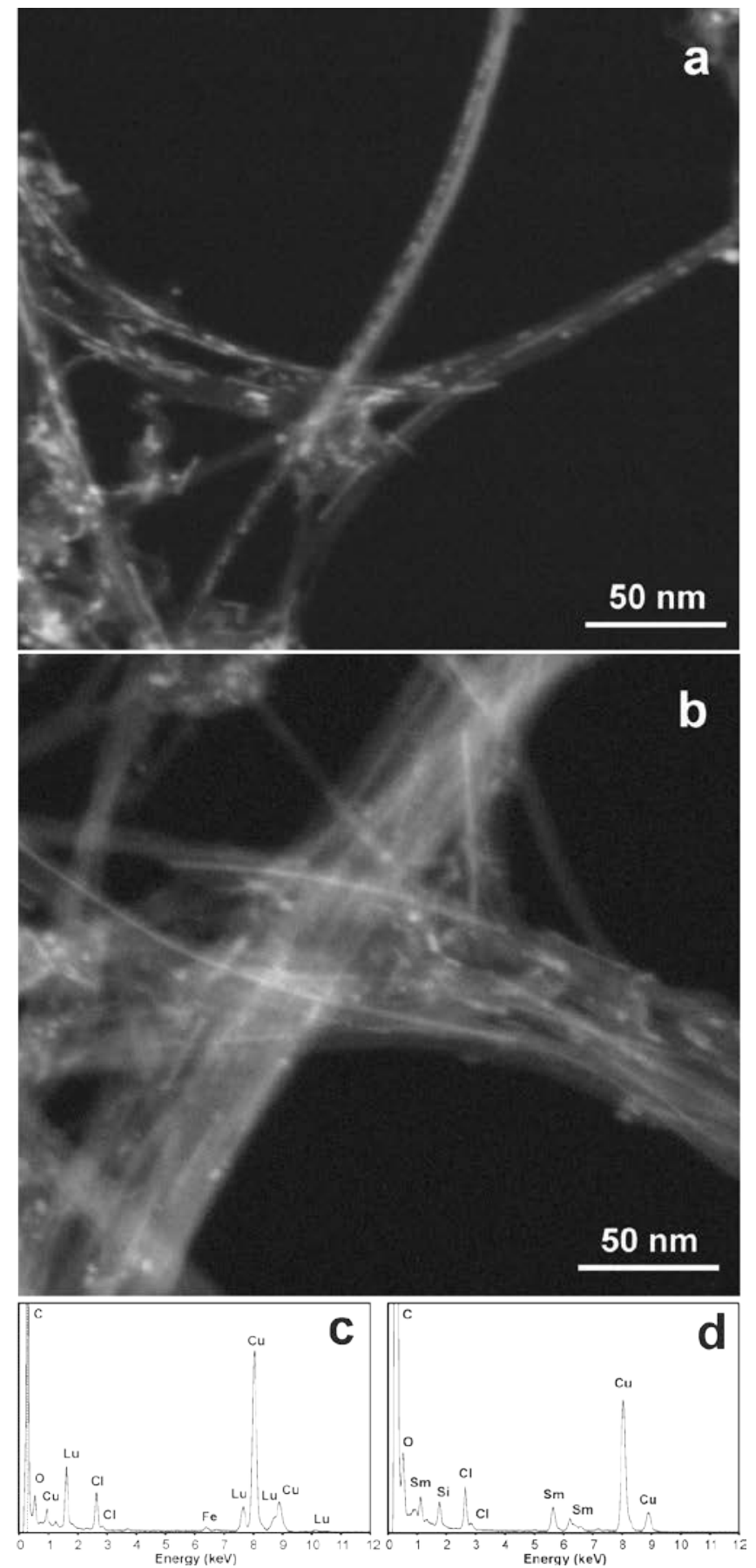

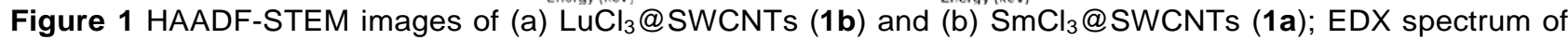
(c) $\mathrm{LuCl}_{3} @$ SWCNTs (1b) and (d) $\mathrm{SmCl}_{3} @ S W C N T s(\mathbf{1 a})$. The Cu peaks arise from the grid employed for the analysis.

Imaging at low operating voltages prevents the damage of carbon nanotubes by electron beam irradiation. HAADF-STEM imaging is a powerful tool that allows the direct visualization of the encapsulated material. ${ }^{34}$ Since the contrast formation of the image is proportional to the atomic number of the element, heavy elements such as lutetium and samarium appear much brighter than carbon from the SWCNTs. Therefore, the bright lines observed on the images correspond to $\mathrm{LuCl}_{3}$ and $\mathrm{SmCl}_{3}$. As it can be seen, these bright lines follow the shape of the SWCNTs, an indication of the successful encapsulation of the payloads. To further confirm the presence of the metal chlorides and assess the purity of the prepared samples, energy dispersive X-ray (EDX) spectra were acquired using a transmission electron microscope (Figure 1c, d). EDX analysis reveals the presence of either $\mathrm{LuCl}_{3}$ or $\mathrm{SmCl}_{3}$ and the absence of impurities apart from a small amount of iron visible in the $\mathrm{LuCl}_{3} @$ SWCNT sample. This Fe content can be attributed to residual catalyst 
nanoparticles used for the growth of the SWCNTs still present after the purification of the SWCNTs. Direct evidence of the confinement of the investigated materials inside carbon nanotubes was provided by high resolution TEM imaging (see ESI Figure S2).

\section{Functionalization of Sm-filled SWCNTs}

The functionalization of the external surface of filled SWCNTs was then performed by nitrene reaction. This is a $[2+1]$ cycloaddition involving reactive nitrenes leading to the formation of aziridine rings on the CNT sidewalls. ${ }^{35,36}$ This reaction does not require harsh conditions and occurs at the unsaturated bonds of the nanotubes, without engendering major defects and thus preserving the sealed structure of the nanotubes. The functionalization of nanotubes by nitrene reaction has been reported, either using azidocarbonates ${ }^{35}$ or organic azides ${ }^{36}$ as starting material, and affording good degree of functionalization in both cases. As precursor for the nitrene reaction we employed the organic azide $\mathbf{S 3}$, which bears the reacting azide group at one terminus, a phthalimide-protected amino group at the other terminus connected by a triethylene glycol (TEG) chain (Scheme 1). Though TEG is a short chain, its hydrophilic character can enhance the nanotube water-dispersibility upon functionalization. Furthermore, the use of short ethylene glycol chains offers the advantage of minimizing the adsorption phenomena and facilitates the thorough removal of unreacted precursor with a shorter work-up, compared to longer ethylene glycol chains. The azide precursor S3 was synthesized starting from commercially available [(chloroethoxy)ethoxy]ethanol, according to a reported procedure (see ESI Scheme S1). ${ }^{37}$

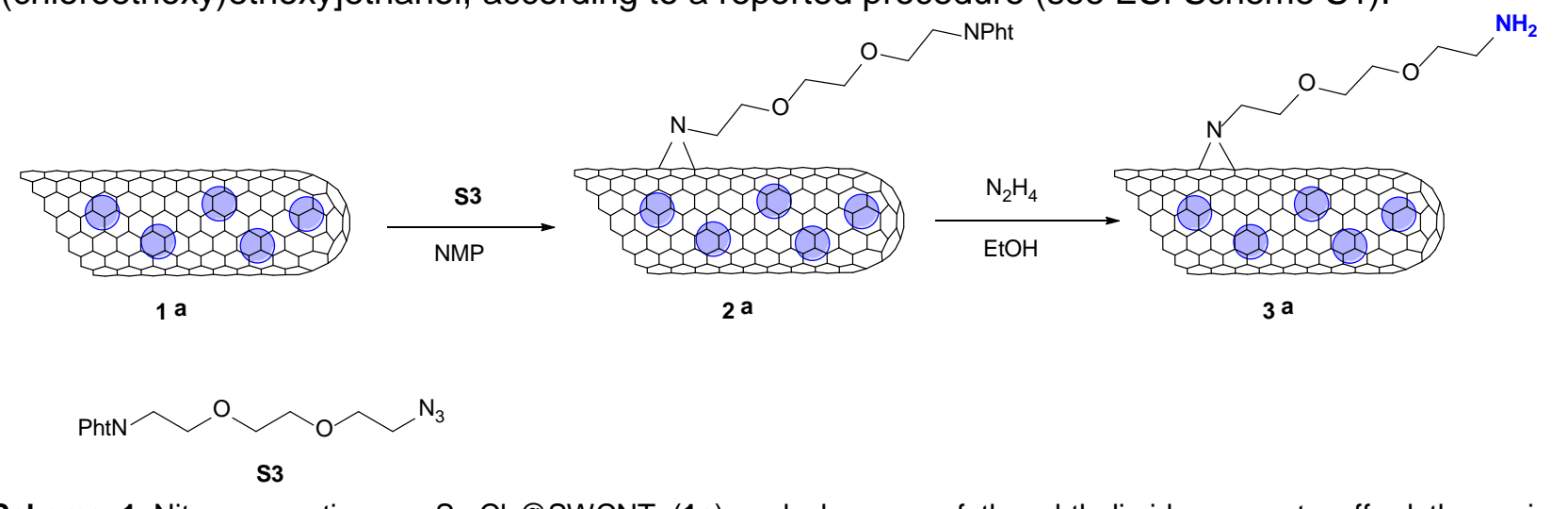

Scheme 1 Nitrene reaction on $\mathrm{SmCl}_{3} @ S W C N T$ (1a) and cleavage of the phthalimide group to afford the amino functionalized SmCl $@$ @SWCNT-NH $\mathrm{N}_{2}(\mathbf{3 a})$.

For nitrene reaction, $\mathrm{SmCl}_{3} @ S W C N T s$ (1a) were dispersed in dry NMP by sonication under inert atmosphere and, after addition of a 20 -fold mass excess of azide $\mathbf{5 3}$, the mixture was reacted at $200^{\circ} \mathrm{C}$ for 12 hours (Scheme 1). As nitrene reaction can proceed also by radical addition, it is important to ensure an inert atmosphere within the reaction vessels, to prevent the highly reactive species from reacting with oxygen. ${ }^{38}$ The work-up of the reaction was carried out with thorough washing of compound $\mathbf{1 a}$ and dialysis against $\mathrm{ddH}_{2} \mathrm{O}$ (to remove the adsorbed TEG chain). The phthalimide protecting group was cleaved by treating with hydrazine a dispersion of $\mathrm{SmCl}_{3} @ S W C N T-P h t(\mathbf{2 a})$ in ethanol (Scheme 1). The loading of free amines determined by colorimetric Kaiser test was $90 \mu \mathrm{mol} / \mathrm{g}$, corresponding to $110 \mu \mathrm{mol} / \mathrm{g}$ of carbon taking into account the filling yield. The amine-functionalized CNTs (3a) and the Pht-protected precursor (2a) were also characterized by TGA performed this time under inert atmosphere, confirming the occurrence of the functionalization (see ESI Figure S3). In order to have a further proof of the presence of free amines on functionalized SWCNTs and of their availability for further derivatization, we coupled the amines with an iodinated tagging molecule to enable atomic-scale detection by Z-contrast STEM. ${ }^{15,39}$ The results of this experiment are described in detail in the ESI.

\section{Synthesis and characterization of filled SWCNT-antibody conjugates}

In a recent report, Bonifazi and co-workers succeeded in conjugating Cetuximab to functionalized MWCNTs by carbodiimide-assisted amidation between the carboxylic groups on the antibody and the amino groups present onto CNTs. ${ }^{21}$ Molecular dynamics simulations of the structure of Cetuximab revealed that $40 \%$ of carboxylic acids are buried in the mAb tertiary structure, while the 
remaining $60 \%$ is homogenously distributed on the outer surface and therefore potentially reactive toward amidation reactions with amines. ${ }^{21}$ Their approach seemed convenient to us, as our functionalized SWCNTs do also display free amino groups on the sidewalls and this would allow to achieve the final conjugate in only one step. Amino-functionalized $\mathrm{SmCl}_{3} @ S W C N T-\mathrm{NH}_{2}(3 a)$ were thus incubated for $24 \mathrm{~h}$ with Cetuximab in the presence of 1-(3-dimethylaminopropyl)-3ethylcarbodiimide hydrochloride $(\mathrm{EDC} \times \mathrm{HCl})$ and $\mathrm{N}$-hydroxysulfosuccinimide (NHSS) in buffer conditions (Scheme 2). Since proteins can have a strong affinity for CNTs, we carried out a control reaction to check if non-covalent immobilization of the antibody also occurred. For this purpose, the conjugate $\mathrm{SmCl}_{3} @ S W C N T-\mathrm{NH}_{2}$ (3a) was mixed with Cetuximab in the absence of coupling reagents (Scheme 2), under the same conditions of the covalent reaction.

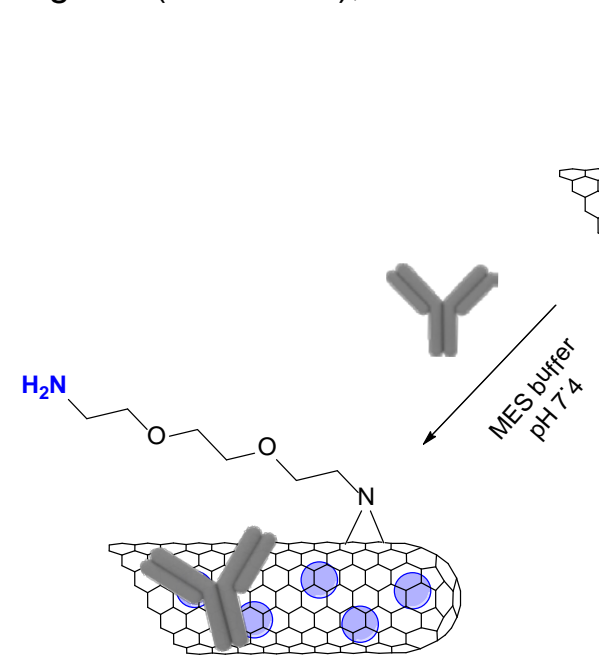

5 a

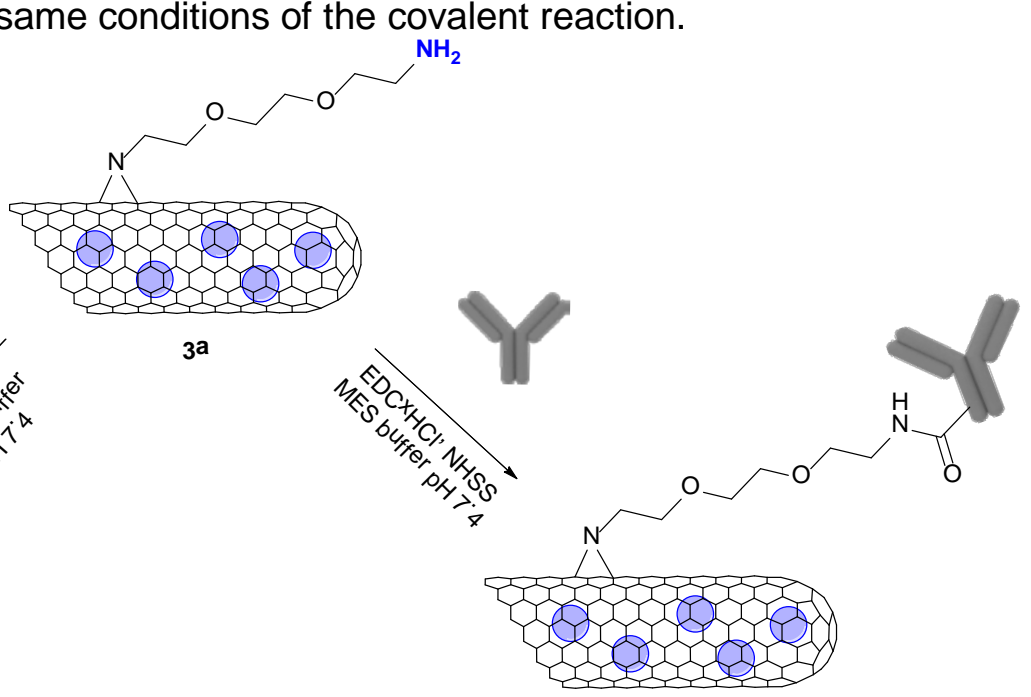

$4 a$

Scheme 2 Covalent derivatization of $\mathrm{SmCl}_{3} @ S W C N T-\mathrm{SH}_{2}(3 \mathrm{a})$ with Cetuximab forming $\mathrm{SmCl}_{3} @ S W C N T-\mathrm{mAb}(4 \mathrm{a})$ and control reaction in the absence of coupling reagents forming the non-covalent complex $\mathrm{SmCl}_{3} @ \mathrm{SWCNT} / \mathrm{mAb}(5 \mathrm{a})$.

By comparing the weight loss of $\mathrm{SmCl}_{3} @ S W C N T-m A b(\mathbf{4 a})$ (obtained by covalent amidation) with that of the precursor (3a), we estimated that the loading of antibody on SWCNTs was $250 \mathrm{mg} / \mathrm{g}$ (407 mg/g of C, taking into account the filling yield) (Figure 2). However, the TG curve of the noncovalent conjugate $\mathrm{SmCl}_{3} @ \mathrm{SWCNT} / \mathrm{mAb}$ (5a) also displayed a significant weight loss, which corresponds to a loading of mAb of $200 \mathrm{mg} / \mathrm{g}$ (305 mg/g of C). This result suggests that a nonnegligible amount of antibody is absorbed onto the nanotubes and could not be removed despite the thorough washing and dialysis steps. However, SmCl${ }_{3} @ S W C N T-m A b(\mathbf{4 a})$ was remarkably well-dispersed in PBS buffer, and the dispersion was stable for longer time compared to the corresponding non-covalent conjugate (5a).

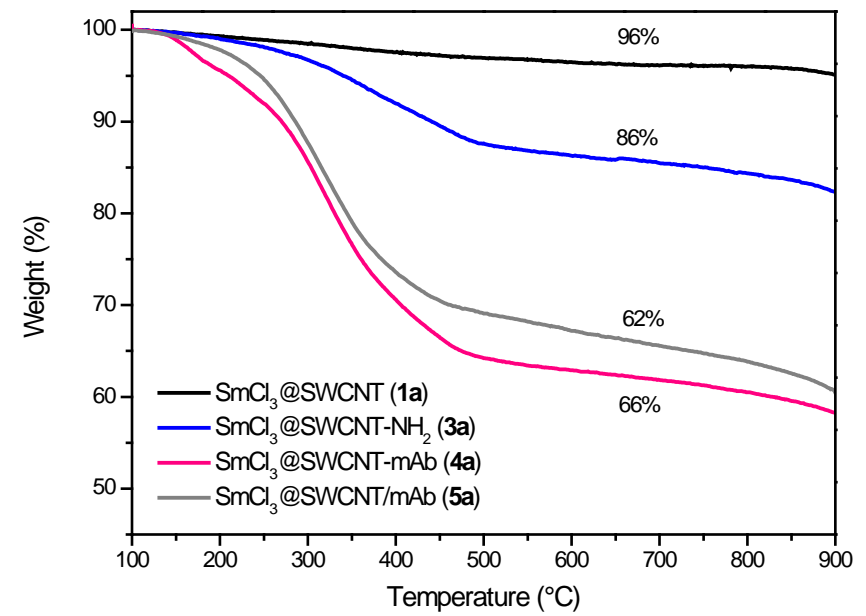

Figure 2 TG curves of pristine $\mathrm{SmCl}_{3} @ S W C N T s$ and conjugates $\mathrm{SmCl}_{3} @ S W C N T-\mathrm{NH}_{2}(\mathbf{3 a}), \mathrm{SmCl}_{3} @ S W C N T-m A b(4 a)$ and $\mathrm{SmCl}_{3} @ S W C N T / \mathrm{mAb}(5 \mathrm{a})$. The percentages correspond to the weight loss observed at $650^{\circ} \mathrm{C}$. 
The mAb immobilization was then evaluated by gel electrophoresis for both $\mathrm{SmCl}_{3} @ S W C N T-m A b$ (4a) and $\mathrm{SmCl}_{3} @ S W C N T / m A b$ (5a) under non-reducing conditions (Figure 3). In the case of the non-covalent conjugate (5a) (lane 4), the unbound antibody is free to migrate through the gel, and the corresponding band is clearly visible at the correct size position (ca. $150 \mathrm{kDa}$ ). Whereas, for the covalent conjugate (4a), no distinct band can be seen in correspondence to the mAb position. This suggests that for $\mathrm{SmCl}_{3} @ S W C N T-m A b(\mathbf{4 a})$, most of Cetuximab is covalently bound to the CNTs, and cannot therefore migrate through the gel. However, the presence of a small amount of non-conjugated mAb cannot be excluded, and it is probably responsible for the light shadows visible in lane 3.

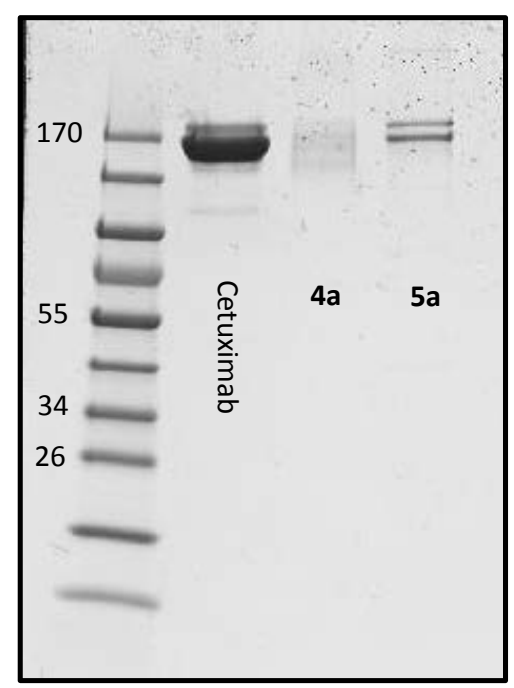

Figure $3 \mathrm{Gel}$ electrophoresis of Cetuximab and conjugates $\mathrm{SmCl}_{3} @ \mathrm{SWCNT}-\mathrm{mAb}(\mathbf{4 a})$ and $\mathrm{SmCl} 3 \mathrm{~S}$ SWCNT/mAb (5a) run under non-reducing conditions at $150 \mathrm{~V}$. Gel stained with Coomassie blue. Protein ladder is on lane 1 (molecular weights are expressed in $\mathrm{kDa}$ ).

We further characterized both antibody-SWCNT conjugates by electron microscopy, performing an immunostaining with a secondary antibody conjugated with gold nanoparticles (AuNPs). This experiment had the double goal of allowing to visualize the Cetuximab attached to the nanotubes and to prove its ability to recognize a specific anti-antibody. The antibody-functionalized conjugate $\mathrm{SmCl}_{3} @ S W C N T-m A b(4 a)$ and the control complex SmCl ${ }_{3} @ S W C N T / m A b(5 a)$ were stained with an anti-human IgG linked with colloidal AuNPs of $15 \mathrm{~nm}$ in diameter, able to recognize Cetuximab. As a further control, the same samples were separately stained with an anti-rabbit IgG/AuNPs (15 $\mathrm{nm}$ diameter), which instead is not specific toward human IgGs. By TEM imaging of $\mathrm{SmCl}_{3} @ S W C N T-m A b$ (4a) stained with anti-human IgG/AuNPs, a multitude of black dots corresponding to the AuNPs were visible all along the nanotubes (Figure 4). In the corresponding HAADF STEM images it is possible to distinctly recognize both the AuNPs as bright large dots, and the samarium-filling. Almost no AuNPs are visible in the images corresponding to $\mathrm{SmCl}_{3} @ S W C N T-m A b(\mathbf{4 a})$ incubated with the anti-rabbit IgG, proving that there is no unspecific binding between this secondary antibody and Cetuximab, neither adsorption of the IgG onto the CNTs. Interestingly, for the non-covalent conjugate (5a) we did not observe any specific labeling of the secondary anti-human IgG (Figure 4). We hypothesize that the binding sites of the adsorbed $A b$ might be masked and unavailable to the secondary Ab recognition. Overall, these results support our objectives, since only the conjugate obtained by covalent reaction displays clear targeting ability. 

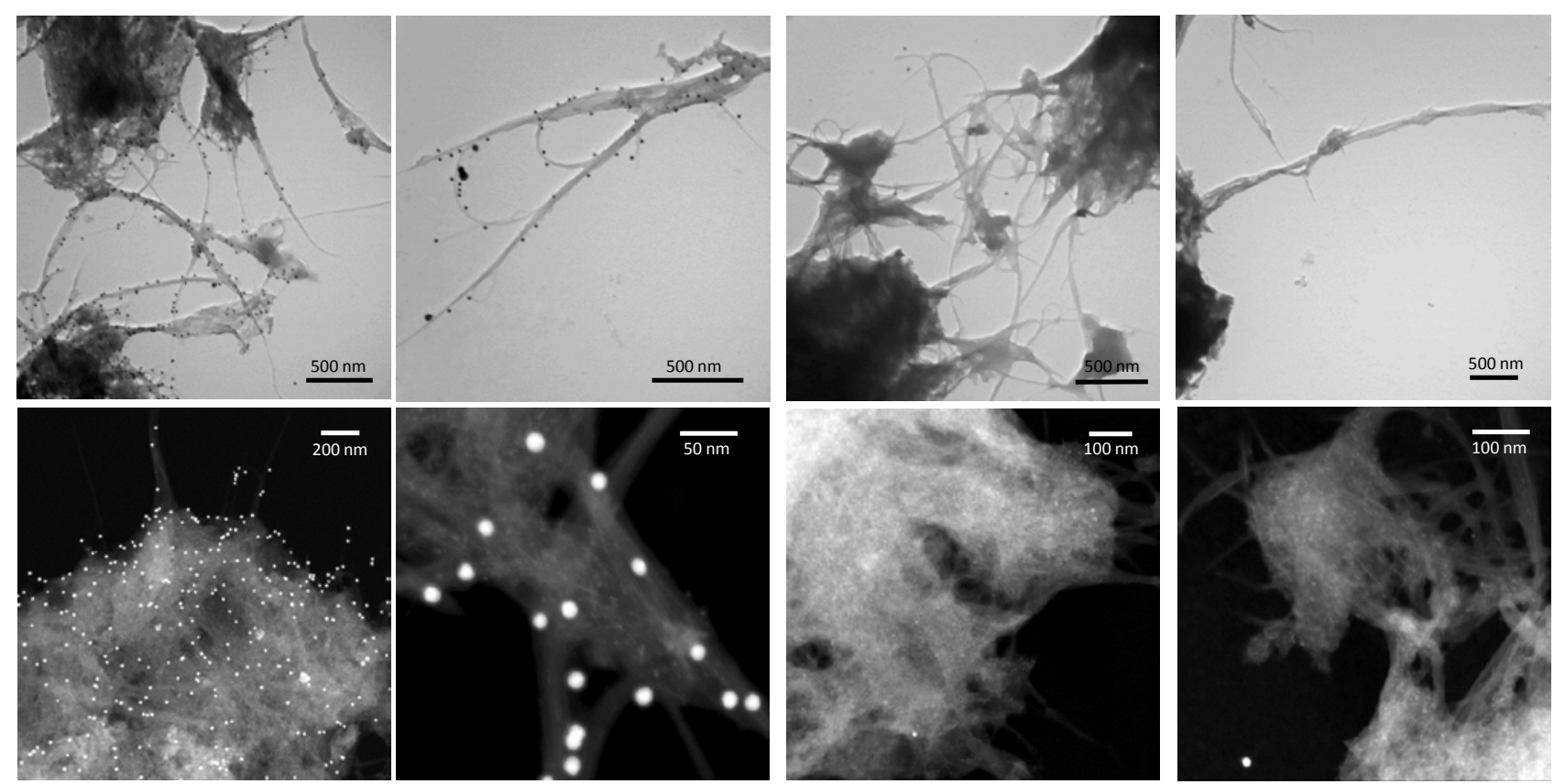

Figure 4 TEM images (top row) and HAADF STEM images (bottom row) of conjugate $\mathrm{SmCl}_{3} @ S W C N T-m A b$ (4a) after staining with an anti-human and an anti-rabbit IgG/AuNPs, and of non-covalent conjugate $\mathrm{SmCl}_{3} @ \mathrm{SWCNT} / \mathrm{mAb}(\mathbf{5 a})$ after staining with anti-human IgG/AuNPs.

Further characterization of $\mathrm{SmCl}_{3} @ S W C N T-m A b(4 a)$ stained with anti-human IgG was performed by EDX analysis and EDX elemental mapping, confirming the presence of both Au and Sm, and their location in the analyzed area (Figure 5). By this immunostaining experiment we could therefore prove that Cetuximab was efficiently immobilized on the Sm-filled SWCNTs and that its affinity toward an appropriate secondary antibody was preserved upon conjugation.
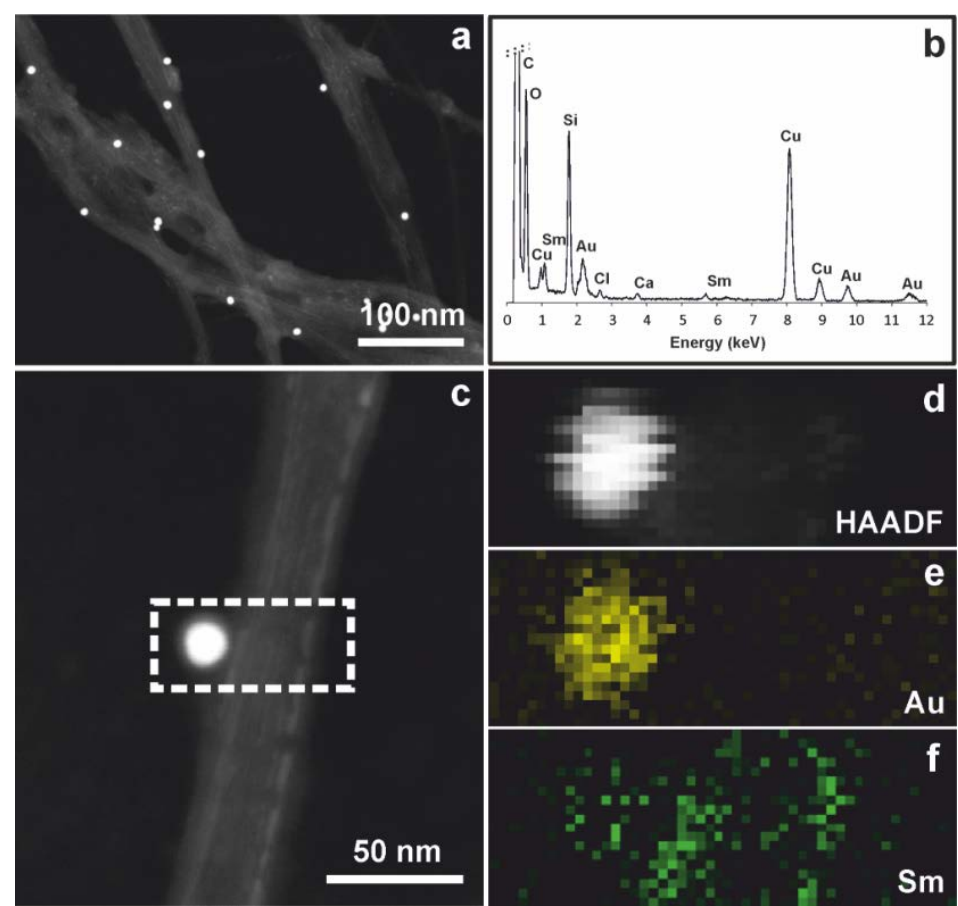

Figure 5 (a) HAADF STEM image of conjugate of $\mathrm{SmCl}_{3} @ S W C N T-m A b$ (4a) after staining with an anti-human IgG/AuNPs and (b) its EDX analysis.(c-f) STEM-EDX mapping on sample (4a). (d) HAADF intensity, (e) Au and (f) Sm mapping on the rectangle area in (c). 
Targeting studies using filled SWCNT-antibody conjugates

With the aim of testing the targeting capability of the antibody-functionalized SWCNTs, U87 glioblastoma cells modified to overexpress EGFR (U87-EGFR+) and Chinese hamster ovary cells $(\mathrm{CHO})$ were selected, the latter chosen as a negative control as they do not express EGFR (see ESI Figure S7). ${ }^{40}$ This important difference between these two cell lines allowed us to compare the uptake and binding of the nanotubes with a focus on their targeting effect. For this purpose, U87EGFR+ and $\mathrm{CHO}$ were treated for 1 and 3 hours with $10 \mu \mathrm{g} / \mathrm{ml}$ of CNTs. As a positive control a concentration of $2.5 \mu \mathrm{g} / \mathrm{ml}$ of Cetuximab was used. After the incubation time, the cells were washed, fixed and treated with the Cy3-goat anti-human IgG $(\mathrm{H}+\mathrm{L})$ fluorescent secondary antibody binding Cetuximab, to allow the analysis of the cellular binding and uptake by flow cytometry. As shown in Figure 6, more than $80 \%$ of U87-EGFR+ were able to bind and internalize Cetuximab covalently or non-covalently bound to SWCNTs, whereas the same behavior occurred in less than $5 \%$ of the $\mathrm{CHO}$ cells in every case. The absence of binding and uptake of the $\mathrm{SmCl}_{3} @ \mathrm{SWCNT}$ $\mathrm{NH}_{2}$ (3a) confirms the specificity of the interaction occurring only in the presence of Cetuximab and exclude a non-specific adsorption of the secondary antibody on the amino-functionalized CNTs, thus confirming the results of the immunostaining (Figure 4).

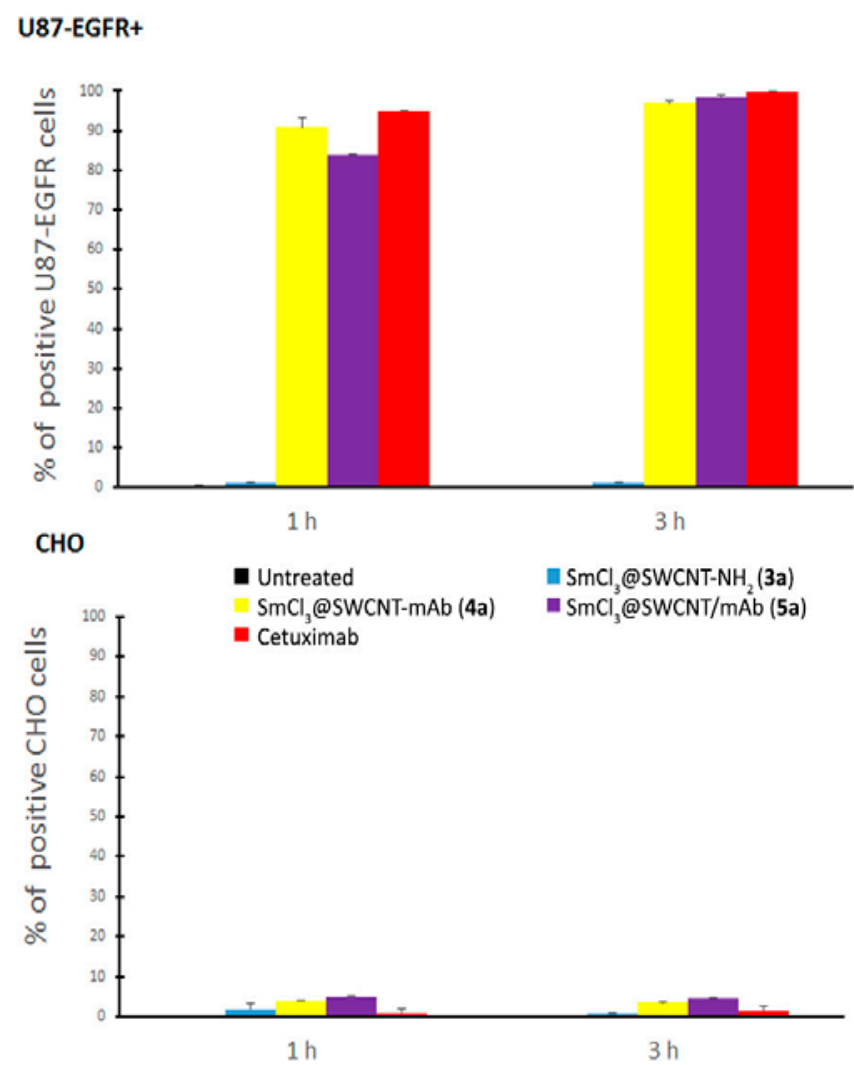

Figure 6 Intracellular uptake of the different functionalized $\mathrm{SmCl}_{3} @$ SWCNTs in U87-EGFR+ cells (top) and $\mathrm{CHO}$ cells (bottom) after $1 \mathrm{~h}$ and $3 \mathrm{~h}$ treatment. Cellular uptake was assessed by analyzing the percentage of positive cells for Cetuximab. NT: Non treated cells.

These results show that $\mathrm{CHO}$ and U87-EGFR+ cells act as good models to analyze the targeting effect and that Cetuximab is in fact targeting the EGFR. In this case, no differences were detected between $\mathrm{SmCl}_{3} @ S W C N T-m A b(\mathbf{4 a})$ and $\mathrm{SmCl}_{3} @ S W C N T / m A b(5 \mathbf{a})$, which may indicate that the $\mathrm{mAb}$ contributed to the targeting in both cases, but probably in a different manner. As shown in

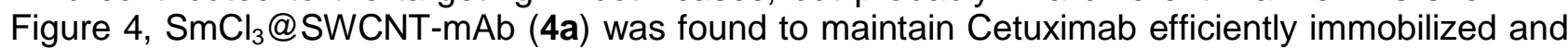
recognized by the secondary antibody, which was not the case of non-covalent complex $\mathrm{SmCl}_{3} @ S W C N T / m A b(5 a)$. Even if both compounds seem to be internalized by U87-EGFR+, it could be hypothesized that part of the mAb on the non-covalent conjugate dissociates from the CNTs and binds the EGFR. As a consequence, the flow cytometry signal might originate from free 
released Cetuximab internalized by the cells. ${ }^{41}$ In this way, we can obtain a signal in the flow cytometry analysis due to the presence of Cetuximab within the cells, which does not necessarily mean the presence of the whole CNT compound in contact with the cells. This could also explain the results obtained by TGA (Figure 2) and gel electrophoresis (Figure 3). In the first characterization, a similar loading of antibody is detected for covalent (4a) and non-covalent (5a) coupling. However, in the second one, the difference observed in the gel bands between both compounds is due to the fact that the non-covalent interaction allows the dissociation of the mAb from the tubes which is not possible in the case of the covalent bond. Similar results were obtained by the analysis of the mean fluorescence intensity data (see ESI Figure S8). The histograms point out the same outcomes observed by analyzing the percentages and do not allow to make a clear difference between the amount of $\mathrm{SmCl}_{3} @ S W C N T-m A b(4 a)$ and $\mathrm{SmCl}_{3} @ S W C N T / m A b$ (5a) that bound and/or entered the cells.

The previous experiments evidenced the presence of the antibody onto the nanotubes and they supported the specific targeting effect provided by the mAb to the CNTs. To further confirm these results, we decided to determine the content of samarium in the cells treated with the covalent conjugate $\mathrm{SmCl}_{3} @ S W C N T-m A b(4 a)$, which represents an indirect measurement of the uptake. For this purpose, U87-EGFR+ and CHO were treated with $25 \mu \mathrm{g} / \mathrm{ml}$ of SmCl $\mathrm{SmSWCNT}_{3} @ \mathrm{mAb}$ (4a). After 24 hours the cells were washed, collected and the intracellular Sm content was measured by inductively coupled plasma atomic emission spectrometry (ICP-AES). A higher concentration in comparison to the flow cytometry analysis was used for this experiment in order to be above the quantification limits.

The results shown in Table 1 are in good agreement with the previous experiments. It can be observed that a more efficient delivery of the metal contained inside the nanotubes was obtained in the case of U87-EGFR+. Even if a certain amount of Sm was found also in CHO cells, suggesting that a small degree of non-specific uptake occurred, the values of Sm content per cell clearly highlight that U87-EGFR+ cells were more efficient in binding and internalizing the SWCNTs, proving the specific targeting effect of the antibody-functionalization and the ability of the SWCNTS to accumulate intracellularly.

Table 1 ICP-AES results indicating the Sm content in $\mathrm{CHO}$ and U87 cells after incubation for 24 hours with $\mathrm{SmCl}_{3} @ S W C N T-m A b(4 a)(25 \mu \mathrm{g} / \mathrm{ml})$ or without SWCNTs ( $\varnothing$ for control experiments).

\begin{tabular}{ccc}
\hline Cell line & Entry & Sm (pg/cell) \\
\hline $\mathrm{CHO}$ & $\varnothing$ & $<0.10$ \\
$\mathrm{CHO}$ & $\mathrm{SmCl}_{3} @ S W C N T-m A b(4 a)$ & $1.59 \pm 0.04$ \\
U87 & $\varnothing$ & $<0.10$ \\
U87 & $\mathrm{SmCl}_{3} @ S W C N T-m A b(4 a)$ & $5.60 \pm 0.08$ \\
\hline
\end{tabular}

Cytotoxicity of CNTs in U87-EGFR+ and CHO cells

To confirm the uptake abilities of CNTs and to assess their effect on the cells, $\mathrm{SmCl}_{3} @ S W C N T$ $\mathrm{NH}_{2}$ 3a, SmCl $\mathrm{Sm}_{3} @ S W C N T-m A b 4 \mathbf{a}$ and $\mathrm{SmCl}_{3} @ S W C N T / m A b$ 5a were incubated with U87-EGFR+ and $\mathrm{CHO}$ cells at 10,50 and $100 \mu \mathrm{g} / \mathrm{mL}$ for $24 \mathrm{~h}$ in order to test potential cytotoxicity (see ESI Figure 9). The intracellular LDH content of both cell lines was measured after $24 \mathrm{~h}$ of incubation and $10 \%$ DMSO was used as positive control. No significant reduction of viability was observed for the different compounds at 10,50 and $100 \mu \mathrm{g} / \mathrm{mL}$.

Synthesis and uptake of fluorescently-labeled SWCNT-antibody conjugates

To further investigate the interactions of filled SWCNTs with cells and to assess the internalization mechanism, we decided to derivatize the amino-functionalized CNTs with a fluorescent dye. In order to mimic the previously synthesized mAb-functionalized SWCNTs, we designed a strategy based on the conjugation of a labeled antibody onto the nanotubes. By attaching the dye (i.e. cyanine 5, Cy5) to the amino groups of Cetuximab and then tethering the labeled Cetuximab to the 
filled amino-functionalized SWCNTs (3b) via the carboxylic groups, we could exploit noncompeting binding sites of the antibody. Cy5 was pre-activated to introduce the reactive NHS-ester and then directly added to a buffer solution of Cetuximab for the coupling (see ESI Scheme S3). The labeled antibody [mAb(Cy5)] was thoroughly purified by size-exclusion chromatography and dialysis, to remove the unreacted mAb and Cy5. The degree of labeling (DL) estimated by UV-Vis spectroscopy was 4.4 , meaning that an average of 4.4 molecules of Cy5 was bound to one molecule of Cetuximab. For the immobilization of mAb(Cy5) onto the nanotubes, a batch of SWCNTs filled with $\mathrm{LuCl}_{3}$ was employed. We have decided to use an alternative filled SWCNTs to prove the versatility of our construct. LuCl ${ }_{3} @ S W C N T s(\mathbf{1 b})$ were previously functionalized by the nitrene reaction and phthalimide-deprotected following the previous protocol (see Scheme 1). The amine loading of the so-obtained conjugate $\mathrm{LuCl}_{3} @ S W C N T-\mathrm{NH}_{2}$ (3b) was $146 \mu \mathrm{mol} / \mathrm{g}$ (corresponding to $208 \mu \mathrm{mol} / \mathrm{g}$ of $\mathrm{C}$ ) as estimated by Kaiser test. The labeled antibody mAb(Cy5) was then coupled to $\mathrm{LuCl}_{3} @ S W C N T-\mathrm{NH}_{2}(\mathbf{3 b})$ as previously described, affording $\mathrm{LuCl}_{3} @ S W C N T-$ mAb(Cy5) (4b) (see ESI Scheme S4). During the washing steps (centrifugation, supernatant removal and SWCNT re-dispersion), it was possible to verify the thorough removal of non-reacted mAb by UV-Vis spectroscopy, thanks to the intense UV adsorption of Cy5. The loading of antibody estimated by comparing the TG weight loss of $\mathrm{LuCl}_{3} @ S W C N T-m A b(C y 5)$ (4b) with that of the aminated precursor is $179 \mathrm{mg} / \mathrm{g}$ (311 mg/g of C) (see ESI Figure S10). The characterization was also performed by gel electrophoresis, and the output is in agreement with the previous results, confirming the covalent conjugation of the antibody (see ESI Figure S11).

The newly synthesized fluorescent conjugate represents a useful tool to allow the assessment of the possible entry mechanisms of the CNTs in a quantitative manner by flow cytometry, as well as their intracellular distribution via confocal microscopy. In order to assess a passive and/or an energy-dependent uptake mechanism, U87-EGFR+ and $\mathrm{CHO}$ cells were treated at $37{ }^{\circ} \mathrm{C}$ or $4{ }^{\circ} \mathrm{C}$ for 2 hours with 1, 10 or $25 \mu \mathrm{g} / \mathrm{ml} \mathrm{LuCl}_{3} @ S W C N T-m A b(C y 5)$ (4b) and analyzed by flow cytometry. As displayed in Figure 7, once again, SWCNTs are targeted to U87-EGFR+ cells. In these cells, regarding the percentage of cells that internalized the SWCNTS, no differences were detected between $37{ }^{\circ} \mathrm{C}$ and $4{ }^{\circ} \mathrm{C}$. However, when analyzing the mean fluorescence intensity (see ESI Figure S12), the blocking of active mechanisms at $4{ }^{\circ} \mathrm{C}$ decreased the amount of SWCNTs that were able to enter U87-EGFR+ cells. In the case of $\mathrm{CHO}$ cells, the nanotubes were not able to bind or to enter the cells at the lower temperature, but they did it to a low extent in a concentration dependent manner at $37^{\circ} \mathrm{C}$.

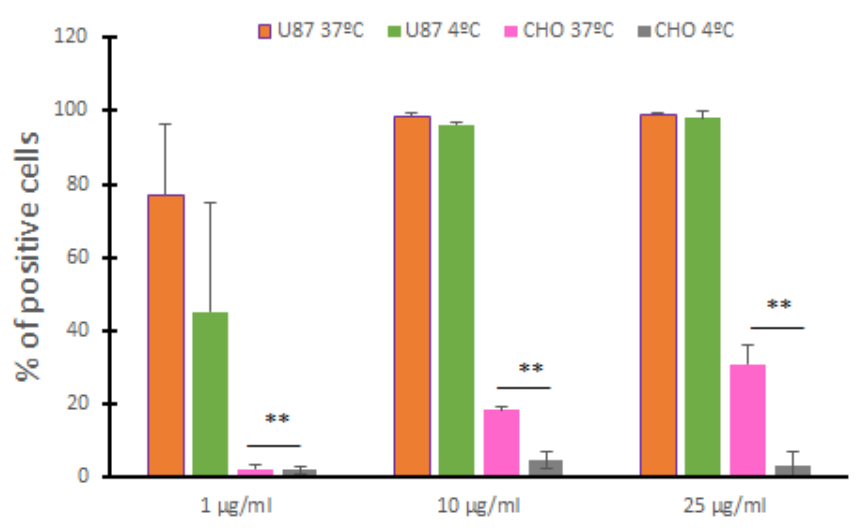

Figure 7 Bars represent the \% of Cy5 positive U87-EGFR+ or $\mathrm{CHO}$ cells after $2 \mathrm{~h}$ incubation at $37{ }^{\circ} \mathrm{C}$ or $4{ }^{\circ} \mathrm{C}$ with 1,10 or $25 \mu \mathrm{g} / \mathrm{ml}$ of $\mathrm{LuCl}_{3} @ S W C N T-m A b(C y 5)(4 b)$. Error bars represent the SD $(n=3) .{ }^{* \star} p<0.01$.

In addition, the fluorescent labeling also allowed us to follow the CNT conjugate $\mathbf{4 b}$ inside the cells once internalized. From the confocal microscopy images obtained after the treatment of $\mathrm{CHO}$ and U87-EGFR+ cells with $25 \mu \mathrm{g} / \mathrm{ml}$ of $\mathrm{LuCl}_{3} @ S W C N T-m A b(C y 5)$ (Figure 8), the results of the uptake experiment can be visually proved. At $37^{\circ} \mathrm{C}$, a higher amount of fluorescent SWCNTs can be 
observed inside U87-EGFR+ cells in comparison to $\mathrm{CHO}$ cells, whereas no differences are visible between the fluorescence at $4{ }^{\circ} \mathrm{C}$ or $37^{\circ} \mathrm{C}$ in U87-EGFR+ cells.

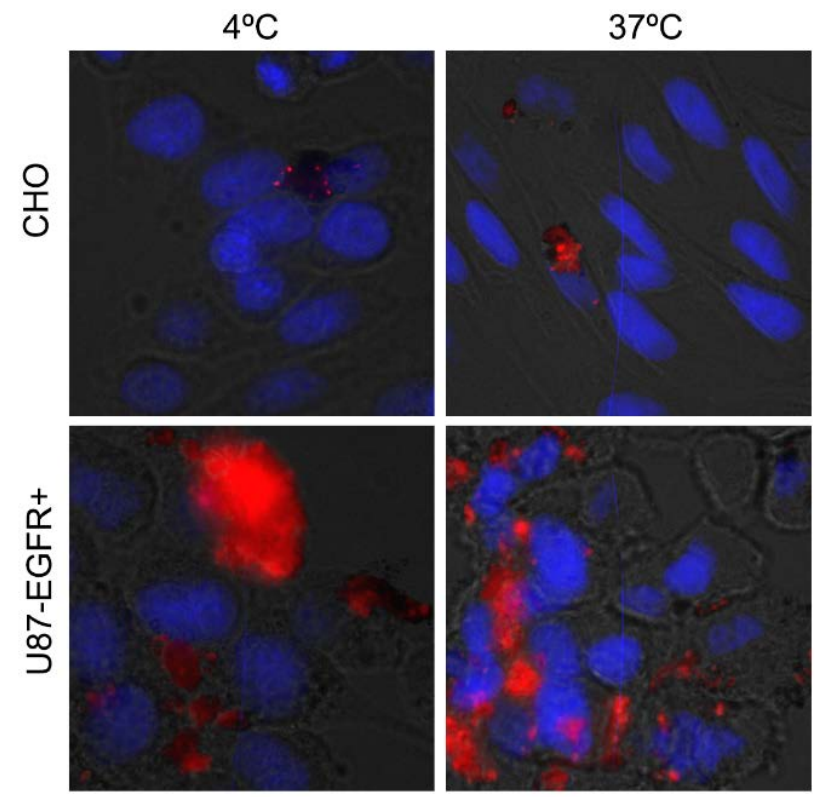

Figure 8 Fluorescence images of $\mathrm{CHO}$ and U87-EGFR+ cells treated for 2 hours with $25 \mu \mathrm{g} / \mathrm{ml}$ LuCl 3 @SWCNT $\mathrm{mAb}(\mathrm{Cy5})(\mathbf{4 b})$ at $4{ }^{\circ} \mathrm{C}$ or $37^{\circ} \mathrm{C}$. Red color corresponds to the Cy5 on the nanotubes, while blue color represents the stained nuclei.

Both experiments show that the antibody functionalization allows the SWCNTs to enter the cells actively as well as passively since they are able to be internalized at $4{ }^{\circ} \mathrm{C}$, a temperature known to block endocytosis. On the contrary, in the case of $\mathrm{CHO}$ cells, functionalized SWCNTs seem to enter via an active mechanism as they only show low levels of cellular uptake at $37^{\circ} \mathrm{C}$. As it has been previously reported, functionalized CNTs can enter the cells via both an active endocytosis and by the so-called "nanoneedle" mechanism, a passive translocation into the cytoplasm. ${ }^{42}$ The adoption of two different mechanisms could be due to the fact that the absence of a targeting in the case of $\mathrm{CHO}$ cells could delay the interaction of the CNTs with the plasma membrane, allowing the formation of clusters of CNTs. As previously suggested by Mu et al., ${ }^{43}$ clustered CNTs would not be able to directly cross the cell membrane and they may need to be endocytosed. The use of a passive mechanism remains in accordance to previously published results. ${ }^{42,44-46}$ Consequently there is no need of endocytosis for the uptake of SWCNTs although, when available, it may favor the internalization.

\section{CONCLUSION}

In summary, we have achieved the filling and sealing of purified SWCNTs with two radionuclide analogues $\left(\mathrm{SmCl}_{3}\right.$ and $\left.\mathrm{LuCl}_{3}\right)$ and investigated their reactivity toward nitrene cycloaddition with an organic azide. We succeeded in the functionalization of both Sm- and Lu-filled CNTs with a biocompatible linker and a targeting monoclonal antibody (Cetuximab) and proved the targeting efficacy of this novel carrier toward cancer cells overexpressing the EGF receptor. Researches on the functionalization of CNTs filled with radioactive material aimed at evaluating the biodistribution and therapeutic effect of these conjugates in vivo will follow in the next future. With this work we propose that the encapsulation of therapeutic or imaging radioisotopes within CNTs and subsequent surface functionalization with targeting ligands could offer a stable and efficient way for the selective delivery of radioisotopes at ultrasensitive doses for therapeutic or diagnostic purposes. After sealing the chosen radionuclides, the external walls of the closed-ended filled carbon nanotubes can be decorated with biologically active molecules in order to convey specific targeting properties and enhance their biocompatibility. We believe that our results will inspire the development of novel nanomaterials for biomedical applications in the areas of cancer diagnosis and therapy. 


\section{EXPERIMENTAL PART}

\section{Materials and Methods}

Chemical vapor deposition grown single-walled carbon nanotubes (SWCNTs) were supplied by Thomas Swan \& Co. Ltd. (Elicarb ${ }^{\circledR}$ ). The as-received material also contained a fraction of doublewalled carbon nanotubes (DWCNTs), amorphous carbon, graphitic particles (carbonaceous crystalline materials having few graphitic layers), and some metal particles. The presence of DWCNTs in the samples has been recently analyzed by Raman spectroscopy [M. Kierkowicz, E. Pach, A. Santidrián, E. Tobías-Rossell, M. Kalbáč, B. Ballesteros and G Tobias, ChemNanoMat, DOI: 10.1002/cnma.201500207.]. Both samarium (III) chloride and lutetium (III) chloride were purchased from Sigma Aldrich (anhydrous, powder, 99.99\% trace metals basis). The chemicals and solvents were obtained from commercial suppliers and used without further purification. Cetuximab was obtained from $\mathrm{KCL}$ (London) as pharmaceutical formulation Erbitux ${ }^{\circledR}$ ( $\mathrm{C}=5$ $\mathrm{mg} / \mathrm{mL}$ ). For the fluorescent tagging, cyanine 5 (Cy5) was provided by the group of Anthony Romieu (Université de Bourgogne in Dijon). The solvents used for synthesis were analytical grade. When anhydrous conditions were required, high quality commercial dry solvents were used. Water was purified using a Millipore filter system MilliQ ${ }^{\circledR}$. When stated, suspensions were sonicated in a water bath $(20 \mathrm{~W}, 40 \mathrm{kHz})$. For the labeled antibody purification, the column was assembled by packing Sephadex G-25 Fine (GE Healthcare) with PBS buffer. For CNT filtration, PTFE membrane from Millipore were employed. If not differently specified, dialysis of CNT compounds was carried out employing membrane with MWCO 12000-14000 Da, purchased from Spectrum Laboratories, Inc. Mini-dialysis and buffer exchange were performed in Slide-A-Lyzer dialysis tubes (10000 MWCO) from Thermo Scientific. Protein concentration was carried out with Amicon Ultra15 centrifugal filters (10000 MWCO) from Millipore. Centrifugation was performed either using an Eppendorf $5804 \mathrm{R}$ apparatus, or a Beckman Avanti J-25 centrifuge equipped with JS-7.5 rotor. The UV-Vis analyses were performed on a Varian Cary 5000 spectrophotometer and the Kaiser test was performed according to reported procedures. ${ }^{47,48}$ TGA under flowing air was performed on a TA Instrument Q5000 IR (for $\mathrm{LuCl}_{3}$ related samples) and on a Netzsch STA 449 F1 Jupiter (for $\mathrm{SmCl}_{3}$ related samples). Measurements were performed on about $5 \mathrm{mg}$ of sample under flowing air by heating at $10^{\circ} \mathrm{C} / \mathrm{min}$ up to $900^{\circ} \mathrm{C}$. TGA under inert atmosphere was performed on a TGA1 (Mettler Toledo) apparatus from $30{ }^{\circ} \mathrm{C}$ to $900{ }^{\circ} \mathrm{C}$ with a ramp of $10{ }^{\circ} \mathrm{C} \cdot \mathrm{min}^{-1}$ under $\mathrm{N}_{2}$ using a flow rate of $50 \mathrm{~mL} / \mathrm{min}$ and platinum pans. In this case, the estimation of the degree of functionalization by TGA was done by taking weight loss values at $650{ }^{\circ} \mathrm{C}$, because up to $600{ }^{\circ} \mathrm{C}$ strong weight losses were still occurring. For TGA of the CNT-antibody conjugates, an aliquot of the conjugate in PBS was previously dialyzed against deionized water to remove the buffer salts and lyophilized. TEM analyses were performed on a Hitachi H7500 microscope (Tokyo, Japan) with an accelerating voltage of $80 \mathrm{kV}$, equipped with an AMT Hamamatsu camera (Tokyo, Japan). HAADF-STEM images were acquired at $20 \mathrm{kV}$ on a FEI Magellan XHR 400L SEM equipped with a dedicated STEM detector. HRTEM micrographs and EDX spectra were acquired on a FEI Tecnai G2 F20 operated at $200 \mathrm{kV}$ and equipped with an EDAX super ultra-thin window (SUTW) X-ray detector. Samples were dispersed in ethanol and deposited on lacey carbon Cu TEM grids (Agar).

\section{Synthesis and characterization of the CNT conjugates}

\section{Preparation of $\mathrm{SmCl}_{3}$ filled SWCNTs (SmCl $@ S W C N T s$ 1a)}

As-received SWCNTs were purified by steam treatment following a previously reported protocol. ${ }^{31}$ Briefly, SWCNTs were spread inside a silica tube which was then placed into a furnace alumina tube. Steam was introduced by bubbling argon through a flask containing hot distilled water. The whole system was initially purged with argon, to remove atmospheric air, before heating the furnace to $900{ }^{\circ} \mathrm{C}$ during $4 \mathrm{~h}$ to allow the purification of the material. The solid powder was collected and treated with $6 \mathrm{M} \mathrm{HCl}$ (Panreac) to dissolve the exposed metal nanoparticles. The purified SWCNTs were collected by filtration through a $0.2 \mu \mathrm{m}$ polycarbonate membrane and thoroughly washed with water until neutral $\mathrm{pH}$. The sample was oven-dried at $80{ }^{\circ} \mathrm{C}$ overnight. Purified SWCNTs were then mixed with samarium (III) chloride (w/w 1:10 respectively) and grinded with an agate mortar and pestle inside a glovebox until the mixture presented a homogeneous color. The resulting mixture was then vacuum sealed inside a silica ampoule and annealed at 900 ${ }^{\circ} \mathrm{C}$ for $12 \mathrm{~h}$. After cooling down the sample, the silica tube was opened and the material was stirred in water at $80^{\circ} \mathrm{C}$ to remove the non-encapsulated $\mathrm{SmCl}_{3}$ external to the SWCNTs. 
Preparation of $\mathrm{LuCl}_{3}$ filled SWCNTs ( $\left.\mathrm{LuCl}_{3} @ S W C N T s \mathbf{1 b}\right)$

As-received SWCNTs were dispersed in fresh piranha solution $\left(\mathrm{H}_{2} \mathrm{SO}_{4} / \mathrm{H}_{2} \mathrm{O}_{2}, 4: 1\right)$ at a concentration of $1 \mathrm{mg} / \mathrm{mL} .{ }^{49}$ The solution was stirred for $2 \mathrm{~h}$ at r.t. and the reaction then quenched with distilled water. The $\mathrm{pH}$ of the solution was adjusted until neutral. The sample was filtered on a polycarbonate membrane and dried in the oven at $80{ }^{\circ} \mathrm{C}$ overnight. Next, the SWCNTs were treated with steam for $1 \mathrm{~h}$ at $900{ }^{\circ} \mathrm{C}$ and refluxed in $6 \mathrm{M} \mathrm{HCl}$ at $110{ }^{\circ} \mathrm{C}$ overnight. The solid sample was collected by filtration and rinsed with distilled water until neutral $\mathrm{pH}$. The purified SWCNTs were filled with lutetium (III) chloride by molten phase capillary filling. SWCNTs were mixed with $\mathrm{LuCl}_{3}$ (w/w 1:10) and grinded with an agate mortar in an argon-filled glovebox. The mixture was sealed under vacuum inside a silica tube. The sample was then annealed in a horizontal furnace at $960{ }^{\circ} \mathrm{C}$ during $12 \mathrm{~h}$. The resulting sample contained filled closed-ended nanotubes ${ }^{30}$ and external crystals of $\mathrm{LuCl}_{3}$. The non-encapsulated material was removed by washing the sample in hot water.

\section{Synthesis of the organic precursor S3}

The synthesis of the organic azide $\mathbf{S} 3$ was carried out following a reported procedure (see ESI for details). ${ }^{37}$

\section{Fluorescent labeling of Cetuximab [mAb(Cy5)]}

A $10 \mathrm{mg} / \mathrm{mL}$ solution of Cy 5 was prepared by dissolving Cy5 (5.99 mg, $7.04 \mu \mathrm{mol})$ in dry DMF (500 $\mu \mathrm{L})$, under argon. DIEA $(12 \mu \mathrm{L})$ and $40 \mu \mathrm{L}$ of a $0.15 \mathrm{M}$ solution of TSTU in dry DMF (corresponding to $7 \mu \mathrm{mol}$ of TSTU) were then added to the Cy5 and the reaction mixture was stirred at r.t. for $4 \mathrm{~h}$, in the dark. The activated Cy5 $(300 \mu \mathrm{L}$, ca. $3 \mathrm{mg})$ was added to a $5 \mathrm{mg} / \mathrm{mL}$ solution of Cetuximab in PBS (6 mL) at pH 8 (adjusted with $1 \mathrm{M} \mathrm{NaHCO}_{3}$ ) and gently stirred for $2 \mathrm{~h}$, in the dark. The reaction mixture was then filtered through a Sephadex G-25 column with PBS (pH 7.4) as elution buffer and the fractions corresponding to the $\mathrm{mAb}(\mathrm{Cy} 5)$ were joined together and concentrated in an Amicon centrifugal filter (MWCO 10000). By measuring the UV-Vis absorbance of the conjugate, the degree of labeling (DL) was calculated according to the formula reported in $\mathrm{ESI}$ and corresponded to 4.4 molecules of Cy5 per mAb.

\section{Synthesis of $\mathrm{SmCl}_{3} @ S W C N T-\mathrm{NH}_{2}(\mathbf{3 a})$ and $L u C l_{3} @ S W C N T-\mathrm{NH}_{2}(\mathbf{3} \boldsymbol{b})$}

In a flame-dried Schlenk tube, filled SWCNTs (1a or $\mathbf{1 b})(30 \mathrm{mg})$ were dispersed in dry NMP (25 $\mathrm{mL}$ ) by sonicating for 15 min under argon. A solution of azide S3 $(560 \mathrm{mg})$ in dry NMP $(5 \mathrm{~mL})$, was then added to the CNT dispersion by syringe and the mixture was stirred at $200{ }^{\circ} \mathrm{C}$ for $12 \mathrm{~h}$. The cooled mixture was then diluted with $\mathrm{EtOH}(15 \mathrm{~mL})$ and filtered $(0.1 \mu \mathrm{m})$. The CNTs recovered on the filter were washed with $\mathrm{EtOH}(x 1), \mathrm{MeOH}(x 2)$ and acetone (x 2) and dialyzed for $48 \mathrm{~h}$ against $d d \mathrm{H}_{2} \mathrm{O}$. The dialyzed nanotubes were recuperated by filtration, washed with $\mathrm{MeOH}(x \quad 1)$ and acetone (x 1) and finally dried under vacuum. The degree of functionalization estimated from the weight loss comparison with pristine filled SWCNTs $(\mathbf{1 a}, \mathbf{1 b})$ is $17.1 \%$ for $\mathrm{SmCl}_{3} @ S W C N T-P h t(\mathbf{2 a})$ and $17.2 \%$ for LuCl 3 @SWCNT-Pht (2b).

For the deprotection, CNTs (28 mg) were dispersed in EtOH $(25 \mathrm{~mL})$ by sonicating for $10 \mathrm{~min}$, and afterwards treated with hydrazine hydrate $(3 \mathrm{~mL})$. The dispersion was stirred at r.t. for $2 \mathrm{~h}$, and then diluted with EtOH $(15 \mathrm{~mL})$ and filtered $(0.1 \mu \mathrm{m})$. The recovered CNTs were washed with $\mathrm{MeOH}(x 2)$ and acetone (x 2), and finally dried under vacuum. The free amine loading calculated by Kaiser test is $90 \mu \mathrm{mol} / \mathrm{g}$ for $\mathrm{SmCl}_{3} @ S W C N T-P h t(3 a)$ and $146 \mu \mathrm{mol} / \mathrm{g}$ for $\mathrm{LuCl}_{3} @ S W C N T-P h t$ (3b).

\section{Synthesis of SmCl ${ }_{3} @ S W C N T-m A b$ (4a) and SmCl $@ S W C N T / m A b$ (5a)}

An aliquot of Erbitux® (2 $\mathrm{mL})$ was submitted to buffer exchange in a Slide-a-Lyzer Mini Device (MWCO 10000) against MES buffer $\mathrm{pH} 7$, in order to bring Cetuximab in the required buffer medium. MES buffer $50 \mathrm{mM}$ was prepared by dissolving MES $(9.76 \mathrm{~g})$ in $\mathrm{dd}_{2} \mathrm{O}(800 \mathrm{~mL})$ and $\mathrm{pH}$ was adjusted to 7 with $10 \mathrm{~N} \mathrm{NaOH}$ before bringing the solution to $1 \mathrm{~L}$ volume.

Conjugate $3 a(16 \mathrm{mg})$ was dispersed in DMF $(1.3 \mathrm{~mL})$ by sonicating for $15 \mathrm{~min}$ in a centrifuge plastic tube. A solution of EDC $\times \mathrm{HCl}(6 \mathrm{mM})$ and NHSS $(4.4 \mathrm{mM})$ in MES $(2.5 \mathrm{~mL})$ was then added to the dispersion under sonication. After $5 \mathrm{~min}$, Cetuximab $(1 \mathrm{mg} / \mathrm{mL}$ in $\mathrm{MES}, 11 \mathrm{~mL})$ was added 
and the mixture was gently stirred at r.t. for $24 \mathrm{~h}$. The reaction mixture was homogenized by sonicating for $30 \mathrm{sec}$ and the CNTs were precipitated by centrifugation ( $4500 \mathrm{rpm}, 10 \mathrm{~min}, 15^{\circ} \mathrm{C}$ ). The supernatant was removed, the CNTs were re-dispersed in PBS $(20 \mathrm{~mL})$ by sonicating for 10 min. Centrifugation, buffer removal and re-dispersion were repeated at least 3 times in order to remove non-reacted antibody. The CNT dispersion was then dialyzed (MWCO $300000 \mathrm{Da}$ ) against PBS for $24 \mathrm{~h}$. The obtained $4 \mathrm{a}$ was finally stored at $4{ }^{\circ} \mathrm{C}$ in PBS solution $(3.5 \mathrm{mg} / \mathrm{mL})$. The loading of antibody estimated by TGA is $250 \mathrm{mg} / \mathrm{g}$.

For the control reaction, the same procedure was carried out proportionally on a smaller amount of $3 \mathbf{a}(3.1 \mathrm{mg})$ and without addition of EDC $\times \mathrm{HCl}$ and $\mathrm{NHSS}$. The obtained $\mathrm{SmCl}_{3} @ S W C N T / m A b(5 a)$ was stored at $4{ }^{\circ} \mathrm{C}$ in PBS solution $(1.57 \mathrm{mg} / \mathrm{mL})$. The loading of antibody determined by TGA is $200 \mathrm{mg} / \mathrm{g}$.

\section{Synthesis of $L u C l_{3} @ S W C N T-m A b(C y 5)$ (4b)}

The labeled antibody [mAb(Cy5)] $(8 \mathrm{~mL}, 3.8 \mathrm{mg} / \mathrm{mL})$ was submitted to buffer exchange in a Slidea-Lyzer Mini Device (MWCO 10000) against $50 \mathrm{mM}$ MES buffer pH 7. Conjugate 3b (4 mg) was dispersed in DMF $(400 \mu \mathrm{L})$ by sonicating for $15 \mathrm{~min}$ in a centrifuge plastic tube. A solution of $\mathrm{EDC} \times \mathrm{HCl}(6 \mathrm{mM})$ and NHSS $(4.4 \mathrm{mM})$ in MES $(800 \mu \mathrm{L})$ was then added to the dispersion under sonication. After $5 \mathrm{~min}, \mathrm{mAb}(\mathrm{Cy} 5)(0.96 \mathrm{mg} / \mathrm{mL}$ in MES, $2.8 \mathrm{~mL})$ was added to the CNT dispersion and the mixture was gently stirred at r.t. for $24 \mathrm{~h}$. The reaction mixture was homogenized by sonicating for $30 \mathrm{sec}$ and the CNTs were precipitated by centrifugation $\left(4500 \mathrm{rpm}, 10 \mathrm{~min}, 12{ }^{\circ} \mathrm{C}\right)$. The supernatant was removed, the CNTs were re-dispersed in PBS $(3 \mathrm{~mL})$ by sonicating for 10 min. Centrifugation, buffer removal and re-dispersion were repeated 4 times and the decanted fractions were analyzed by UV-Vis spectroscopy to check the absence of non-reacted mAb(Cy5). The CNT dispersion was then dialyzed (MWCO $300000 \mathrm{Da}$ ) against PBS for $24 \mathrm{~h}$. The obtained conjugate $4 \mathbf{b}$ was stored at $4{ }^{\circ} \mathrm{C}$ in PBS solution. The loading of antibody was determined by TGA and corresponds to $179 \mathrm{mg} / \mathrm{g}$.

\section{Gel electrophoresis}

Gel electrophoresis was performed using Mini-PROTEAN® TGX ${ }^{\mathrm{TM}}$ 4-20\% Tris-glycine gels purchased by Bio-Rad Laboratories (Hercules, California). Tris-glycine buffer was used to fill the tank. Prior to loading, the samples were added with Laemmli buffer for non-reducing conditions. The first well was always loaded with the protein ladder. The gel was run at a voltage of $150 \mathrm{~V}$ for ca. 60 min and then stained overnight with Coomassie blue. Finally, the staining solution was removed and the gel extensively washed with distilled water to allow the visualization of the protein bands.

\section{Immunostaining}

For the colloidal gold immunostaining, $20 \mu \mathrm{L}$ of CNT dispersion $(20 \mu \mathrm{g} / \mathrm{mL})$ in PBS were dropcasted on the TEM grids and allowed to dry in air. The TEM grids were first incubated with acetylated BSA in ultrapure UPS-WFI water $(1 \% \mathrm{w} / \mathrm{w})$ for $45 \mathrm{~min}$ and then incubated for $2 \mathrm{~h}$ with 20 $\mu \mathrm{L}$ of staining solution (anti-human IgG/AuNP or anti-rabbit IgG/AuNP). The staining solutions were prepared as following: the secondary IgG/AuNP was dissolved in BSA $(0.1 \% \mathrm{w} / \mathrm{w}$ in PBS) in a $1: 50$ volume ratio. After incubation, the excess of immunoglobulin was rinsed away by incubating the grids with $300 \mu \mathrm{L}$ of PBS for 5 min (3 times), and finally with $300 \mu \mathrm{L}$ of $\mathrm{ddH}_{2} \mathrm{O}$. After drying in air, the grids were observed by TEM and STEM.

\section{Biological investigations}

Cell culture

U87-EGFR+ cells were cultured under controlled atmosphere $\left(37^{\circ} \mathrm{C}, 5 \% \mathrm{CO}_{2}\right)$ in Dulbecco's Modified Eagle Medium (DMEM) supplemented with 10\% FBS, $100 \mathrm{U} / \mathrm{ml}$ gentamycin and 1\% Penicillin-Streptomycin, whereas for CHO cell line RPMI 1640 supplemented with 10\% FBS and $1 \%$ Penicillin-Streptomycin was used. When confluency reached $70-80 \%$, cells were tripsinized, and reseeded in 24 well plates at a density of $10^{5}$ cells/well and allowed to adhere overnight (37 ${ }^{\circ} \mathrm{C}, 5 \% \mathrm{CO}_{2}$ ) prior to CNT addition. 


\section{Examination of EGFR expression by Western blot analysis}

$\mathrm{CHO}$ and U87-EGFR cells were cultured in T75 flask. At 80\% confluency, cells were rinsed twice with ice-cold PBS, incubated with $300 \mu \mathrm{L}$ ice-cold RIPA lysis buffer $(150 \mathrm{mM} \mathrm{NaCl}, 0.1 \%$ Triton X$100,0.5 \%$ sodium deoxycholate, $0.1 \%$ SDS, $50 \mathrm{mM}$ Tris- $\mathrm{HCl}, \mathrm{pH}$ 8) containing protease inhibitor (cComplete Ultra, Roche Diagnostics $\mathrm{GmbH}$, Germany). Cells were scrapped out and collected into a vial. After $30 \mathrm{~min}-1 \mathrm{~h}$ incubation on ice, cell solutions were centrifuged at 17949xg for 30 min and the supernatants were collected. The protein concentrations cell samples were determined by BCA assay. Proteins $(30 \mu \mathrm{g})$ from each sample was resolved in $8 \%$ SDS-PAGE gels and transferred to Hybond ECL nitrocellulose membranes (GE Healthcare, UK). The membrane was blocked in 3\% bovine serum albumin (Sigma-Aldrich, UK) at room temperature for $1 \mathrm{~h}$ and then co-incubated with rabbit monoclonal anti-EGFR antibody at 1:1000 dilution (\#4267, Cell Signalling Technology, USA) and anti-GAPDH antibody at 1:5000 dilution (\#14C10, Cell Signalling Technology, USA) overnight on ice. After washing, the membrane were then incubated with the secondary antibody, horseradish peroxidase linked anti-rabbit antibody (\#7074, Cell Signalling Technology, USA) at 1:3000 dilution for 2 hour at room temperature. Protein bands were detected using chemiluminescent kits (Immun-StarTM Chemiluminescent Kit, BioRad, UK) and imaged by ChemiDoc MP imaging system and Image Lab software (BioRad, UK). GAPDH was used as an internal reference (house-keeping) gene.

Uptake studies in vitro by flow cytometry

U87-EGFR+ and $\mathrm{CHO}$ cells were treated with $10 \mu \mathrm{g} / \mathrm{ml}$ of $\mathrm{SmCl}_{3} @ \mathrm{SWCNT}_{-} \mathrm{NH}_{2}$ (3a), $\mathrm{SmCl}_{3} @ S W C N T-m A b(4 a)$ and $\mathrm{SmCl}_{3} @ S W C N T / m A b(5 \mathbf{a})$. As a positive control a concentration of $2.5 \mu \mathrm{g} / \mathrm{ml}$ of Cetuximab (Erbitux®, Merck KGaA) was used. One and 3 hours after the addition of the CNTs, cells were washed twice with PBS and fixed with 4\% paraformaldehyde (PFA) for 15 min at room temperature. Subsequently, cells were permeabilized with Triton X-100 (0.1\% in PBS) for $10 \mathrm{~min}$, blocked with 1\% BSA for $30 \mathrm{~min}$ at room temperature. Finally, cells were incubated for $2 \mathrm{~h}$ with a fluorescent Cy3-goat anti-human IgG $(\mathrm{H}+\mathrm{L})$ (109-165-088-JIR, Stratech Scientific Ltd) secondary antibody to track Cetuximab. The percentage of Cy3 positive cells and the mean fluorescent intensity were determined by acquiring at least 10,000 events using a FACSCalibur flow cytometer (BD, Franklin Lakes, NJ) and analyzing the data with Flowing Software 2.5.1

\section{ICP-AES}

U87-EGFR+ and CHO cells were seeded in quadruplicate onto 24-well plates at a density of $10^{5}$ cells/well and allowed to adhere overnight prior to exposure to $\mathrm{SmCl}_{3} @ S W C N T-m A b$ (4a) (25 $\mu \mathrm{g} / \mathrm{ml})$. $24 \mathrm{~h}$ later cells were extensively washed with cold PBS, tripsinized, collected and stored in a glass vial until analysis. ICP-AES analyses were performed on an Agilent 7500 ce apparatus.

\section{Modified LDH assay}

In order to assess the effect of CNTs on cell viability and proliferation, intracellular lactate dehydrogenase (LDH) content of U87-EGFR+ and CHO cells exposed to CNTs was measured with the following protocol. Cells were seeded at $1 \times 10^{4}$ cells per well in 96 -well plates, incubated overnight at $37^{\circ} \mathrm{C}$ with $5 \% \mathrm{CO}_{2}$ before being treated with CNTs at 10,50 or $100 \mu \mathrm{g} / \mathrm{ml}$ in serum free DMEM media. After $4 \mathrm{~h}$, cells were supplemented with serum $(10 \% \mathrm{v} / \mathrm{v})$ and incubated at $37^{\circ}$ $\mathrm{C}$ with $5 \% \mathrm{CO}_{2}$ for an overall duration of $24 \mathrm{~h}$. After treatment, cell supernatants were discarded and cells were lysed after incubation with $200 \mu \mathrm{L}$ of $0.9 \%$ of Triton X-100/phenol-free DMEM media solution for $1 \mathrm{~h}$ at $37^{\circ} \mathrm{C}$. Lysates were centrifuged at $40,000 \mathrm{xg}$ for $10 \mathrm{~min}$ and the resulting pellets containing both CNT entrapped inside cells and cell debris were discarded. A mix of $50 \mu \mathrm{L}$ of cell lysate supernatant with $50 \mu \mathrm{L}$ of Substrate Mix Solution (CytoTox® kit) was incubated at room temperature and in the dark for 15 min before adding $50 \mu \mathrm{L}$ of Stop Solution (CytoTox® kit). Blank contained $50 \mu \mathrm{l}$ of lysis buffer, $50 \mu \mathrm{l}$ of substrate mix solution and $50 \mu \mathrm{l}$ of stop solution. The absorbance was read at $490 \mathrm{~nm}$ with a microplate reader (Fluostar Omega ${ }^{\circledR}$ ) obtained from BMG LABTECH (Germany). The following formula was used to calculate the percentage of intracellular $\mathrm{LDH}: \%$ of intracellular $\mathrm{LDH}=\left(\mathrm{A}_{490 \mathrm{~nm}}\right.$ of treated cells $-\mathrm{A}_{490 \mathrm{~nm}}$ of blank) / $\left(\mathrm{A}_{490 \mathrm{~nm}}\right.$ of untreated cells $A_{490 n m}$ of blank) $\times 100$. Results were expressed as mean $\pm S D(n=3)$. 
U87-EGFR+ and $\mathrm{CHO}$ cells were seeded onto 24 well/plates $\left(10^{5}\right.$ cells/well) and allowed to adhere overnight. Afterwards, cells were treated with 1,10 or $25 \mu \mathrm{g} / \mathrm{ml}$ of LuCl $\mathrm{LSWWCNT}_{3}$ SWAb(Cy5) (4b) and incubated either at $4{ }^{\circ} \mathrm{C}$ or at $37{ }^{\circ} \mathrm{C}$ for $2 \mathrm{~h}$ to compare the non-active and active uptake mechanisms, respectively. Cells were then extensively washed with cold PBS, tripsinized, collected and analyzed with Gallios flow cytometer (Beckman Coulter, Villepinte, France). The percentage of fluorescent cells and their mean fluorescent intensity was determined by acquiring at least 10,000 events and analyzing the data with Flowing Software 2.5.1.

\section{Confocal microscopy experiment}

Cells were seeded onto polystyrene culture chambers (Falcon 354108) and allowed to adhere overnight $\left(10^{5}\right.$ cells/well). The conjugate $\mathrm{LuCl}_{3} @ S W C N T-m A b(C y 5)(4 \mathbf{b})(25 \mu \mathrm{g} / \mathrm{ml})$ was then added and incubated for $2 \mathrm{~h}$ either at $4{ }^{\circ} \mathrm{C}$ or $37^{\circ} \mathrm{C}$. Cells were then extensively washed with cold PBS, fixed with 4\% PFA and treated with DAPI (0.1\% in PBS) in order to stain the nuclei of the cells. Images were obtained with an Axio Observer Z1 microscope (Zeiss) connected to a Spinning Disk Confocal head (Yokogawa) and ImageJ software was used for further analyses.

\section{ACKNOWLEDGEMENTS}

The research leading to these results has received funding from the People Programme (Marie Curie Actions) of the European Union's Seventh Framework Programme FP7/2007-2013/ under REA grant agreement $n^{\circ} 290023$ (RADDEL). This work was partly supported by the Centre National de la Recherche Scientifique (CNRS), by the Agence Nationale de la Recherche (ANR) through the LabEx project Chemistry of Complex Systems (ANR-10-LABX-0026_CSC) and by the International Center for Frontier Research in Chemistry (icFRC). ICN2 acknowledges support from the Severo Ochoa Program (MINECO, Grant SEV-2013-0295). KCL acknowledges support from WCR. The authors are grateful to Thomas Swan \& Co. Ltd. for providing Elicarb ${ }^{\circledR}$ SWCNTs. MM, $\mathrm{MK}$ and EP work has been done as a part of PhD program in Materials Sciences at UAB.

\section{REFERENCES}

1. K. Kostarelos, A. Bianco, and M. Prato, Nat. Nanotechnol., 2009, 4, 627-633.

2. E. Heister, E. W. Brunner, G. R. Dieckmann, I. Jurewicz, and A. B. Dalton, ACS Appl. Mater. Interfaces, 2013, 5, 1870-91.

3. A. Eatemadi, H. Daraee, H. Karimkhanloo, M. Kouhi, N. Zarghami, A. Akbarzadeh, M. Abasi, Y. Hanifehpour, and S. W. Joo, Nanoscale Res. Lett., 2014, 9, 393.

4. G. Hong, S. Diao, A. L. Antaris, and H. Dai, Chem. Rev., 2015, 115, 10816-10906.

5. W. Zhang, Z. Zhang, and Y. Zhang, Nanoscale Res. Lett., 2011, 6, 555.

6. K. Bates and K. Kostarelos, Adv. Drug Deliv. Rev., 2013, 65, 2023-33.

7. C. Fabbro, H. Ali-Boucetta, T. Da Ros, K. Kostarelos, A. Bianco, and M. Prato, Chem. Commun., 2012, 48, 3911-26.

8. R. Singh, D. Pantarotto, L. Lacerda, G. Pastorin, C. Klumpp, M. Prato, A. Bianco, and K. Kostarelos, Proc. Natl. Acad. Sci. U. S. A., 2006, 103, 3357-62.

9. A. Ruggiero, C. H. Villa, J. P. Holland, S. R. Sprinkle, C. May, J. S. Lewis, D. A. Scheinberg, and M. R. McDevitt, Int. J. Nanomedicine, 2010, 5, 783-802.

10. M. R. McDevitt, D. Chattopadhyay, J. S. Jaggi, R. D. Finn, P. B. Zanzonico, C. Villa, D. Rey, J. Mendenhall, C. A. Batt, J. T. Njardarson, and D. A. Scheinberg, PLoS One, 2007, 2, e907.

11. X. Deng, S. Yang, H. Nie, H. Wang, and Y. Liu, Nanotechnology, 2008, 19, 075101.

12. Z. Liu, W. Cai, L. He, N. Nakayama, K. Chen, X. Sun, X. Chen, and H. Dai, Nat. Nanotechnol., 2007, 2, 47-52.

13. M. Das, S. R. Datir, R. P. Singh, and S. Jain, Mol. Pharm., 2013, 10, $2543-57$.

14. J. T.-W. Wang, L. Cabana, M. Bourgognon, H. Kafa, A. Protti, K. Venner, A. M. Shah, J. K. Sosabowski, S. J. Mather, A. Roig, X. Ke, G. Van Tendeloo, R. T. M. de Rosales, G. Tobias, K. T. AlJamal, G. Van Tendeloo, R. T. M. de Rosales, G. Tobias, and K. T. Al-Jamal, Adv. Funct. Mater., 2014, 24, 1880-1894.

15. S. Y. Hong, G. Tobias, K. T. Al-Jamal, B. Ballesteros, H. Ali-Boucetta, S. Lozano-Perez, P. D. Nellist, R. B. Sim, C. Finucane, S. J. Mather, M. L. H. Green, K. Kostarelos, and B. G. Davis, Nat. Mater., 2010, 9, 485-90.

16. J. Rubin Grandis, M. F. Melhem, W. E. Gooding, R. Day, V. A. Holst, M. M. Wagener, S. D. Drenning, and D. J. Tweardy, J. Natl. Cancer Inst., 1998, 90, 824-32.

17. T. K. Owonikoko, S.-Y. Sun, and S. S. Ramalingam, Clin. Lung Cancer, 2009, 10, $230-8$. 
18. A. M. Egloff and J. R. Grandis, Semin. Oncol., 2008, 35, 286-97.

19. F. Ciardiello and G. Tortora, Clin. Cancer Res., 2001, 7, 2958-70.

20. W. Sihver, J. Pietzsch, M. Krause, M. Baumann, J. Steinbach, and H.-J. Pietzsch, Pharmaceuticals, 2014, 7, 311-38.

21. R. Marega, F. De Leo, F. Pineux, J. Sgrignani, A. Magistrato, A. D. Naik, Y. Garcia, L. Flamant, C. Michiels, and D. Bonifazi, Adv. Funct. Mater., 2013, 23, 3173-3184.

22. P.-C. Lee, Y.-C. Chiou, J.-M. Wong, C.-L. Peng, and M.-J. Shieh, Biomaterials, 2013, 34, $8756-65$.

23. Z. Liu, X. Li, S. M. Tabakman, K. Jiang, S. Fan, and H. Dai, J. Am. Chem. Soc., 2008, 130, 1354013541.

24. M. del C. Giménez-López, F. Moro, A. La Torre, C. J. Gómez-García, P. D. Brown, J. van Slageren, and A. N. Khlobystov, Nat. Commun., 2011, 2, 407.

25. A. Vyalikh, A. U. B. Wolter, S. Hampel, D. Haase, M. Ritschel, A. Leonhardt, H.-J. Grafe, A. Taylor, K. Krämer, B. Büchner, and R. Klingeler, Nanomedicine UK, 2008, 3, 321-7.

26. M. Martincic and G. Tobias, Expert Opin. Drug Deliv., 2015, 12, 563-81.

27. B. S. Wong, S. L. Yoong, A. Jagusiak, T. Panczyk, H. K. Ho, W. H. Ang, and G. Pastorin, Adv. Drug Deliv. Rev., 2013, 65, 1964-2015.

28. P. M. Ajayan and S. lijima, Nature, 1993, 361, 333-334.

29. D. Ugarte, T. Stöckli, J. M. Bonard, A. Châtelain, and W. A. de Heer, Appl. Phys. A Mater. Sci. Process., 1998, 67, 101-105.

30. L. Shao, G. Tobias, Y. Huh, and M. L. H. Green, Carbon, 2006, 44, 2855-2858.

31. B. Ballesteros, G. Tobias, L. Shao, E. Pellicer, J. Nogués, E. Mendoza, and M. L. H. Green, Small, 2008, 4, 1501-1506.

32. L. Shao, G. Tobias, C. G. Salzmann, B. Ballesteros, S. Y. Hong, A. Crossley, B. G. Davis, and M. L. H. Green, Chem. Commun., 2007, 5090-2.

33. B. Ballesteros, G. Tobias, M. A. H. Ward, and M. L. H. Green, J. Phys. Chem. C, 2009, 113, 26532656.

34. X. Fan, E. C. Dickey, P. C. Eklund, K. A. Williams, L. Grigorian, R. Buczko, S. T. Pantelides, and S. J. Pennycook, Phys. Rev. Lett., 2000, 84, 4621-4624.

35. M. Holzinger, J. Abraham, P. Whelan, R. Graupner, L. Ley, F. Hennrich, M. Kappes, and A. Hirsch, J. Am. Chem. Soc., 2003, 125, 8566-80.

36. C. Gao, H. He, L. Zhou, X. Zheng, and Y. Zhang, Chem. Mater., 2009, 21, 360-370.

37. G. Lu, S. Lam, and K. Burgess, Chem. Commun., 2006, 1652-4.

38. J. Liu, C. M. Hadad, and M. S. Platz, Org. Lett., 2005, 7, 549-52.

39. S. Y. Hong, G. Tobias, B. Ballesteros, F. El Oualid, J. C. Errey, K. J. Doores, A. I. Kirkland, P. D. Nellist, M. L. H. Green, and B. G. Davis, J. Am. Chem. Soc., 2007, 129, 10966-7.

40. A. W. Krug, C. Schuster, B. Gassner, R. Freudinger, S. Mildenberger, J. Troppmair, and M. Gekle, J. Biol. Chem., 2002, 277, 45892-7.

41. N. I. Goldstein, M. Prewett, K. Zuklys, P. Rockwell, and J. Mendelsohn, Clin. Cancer Res., 1995, 1, 1311-8.

42. L. Lacerda, J. Russier, G. Pastorin, M. A. Herrero, E. Venturelli, H. Dumortier, K. T. Al-Jamal, M. Prato, K. Kostarelos, and A. Bianco, Biomaterials, 2012, 33, 3334-43.

43. Q. Mu, D. L. Broughton, and B. Yan, Nano Lett., 2009, 9, 4370-5.

44. K. Kostarelos, L. Lacerda, G. Pastorin, W. Wu, S. Wieckowski, J. Luangsivilay, S. Godefroy, D. Pantarotto, J.-P. Briand, S. Muller, M. Prato, and A. Bianco, Nat. Nanotechnol., 2007, 2, $108-13$.

45. D. Pantarotto, J.-P. Briand, M. Prato, and A. Bianco, Chem. Commun., 2004, 16-7.

46. X. Jiang, G. Wang, R. Liu, Y. Wang, Y. Wang, X. Qiu, and X. Gao, Nanoscale, 2013, 5, $7256-64$.

47. E. Kaiser, R. L. Colescott, C. D. Bossinger, and P. I. Cook, Anal. Biochem., 1970, 34, 595-598.

48. C. Samorì, R. Sainz, C. Ménard-Moyon, F. M. Toma, E. Venturelli, P. Singh, M. Ballestri, M. Prato, and A. Bianco, Carbon, 2010, 48, 2447-2454.

49. K. J. Ziegler, Z. Gu, H. Peng, E. L. Flor, R. H. Hauge, and R. E. Smalley, J. Am. Chem. Soc., 2005, 127, 1541-7. 